ORIGINAL PAPERS

報 文

(48)

液相化学平衡組成の計算法*

箖清**

要旨： 最近豊富に菁皘されてきた気体あるいは蒸気の熱力学的の数值を用いて熱力学的数值の少い液相反応の平衡 組成を計算する方法を述へる。気液兩相が蒸発平衡に在り，また気相は理想気体，液相は理相溶液として取り扱える わのとすると，次式が導かれる。

$$
K_{p}=K_{N(l)} \cdot K_{\text {v.p. }}
$$

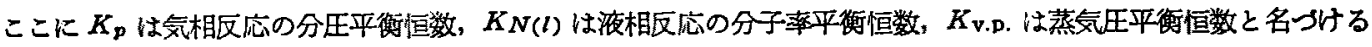
新函数で，反心に与かる成分の蒸気压を以て平衡恒数と同样に表わした比例項である。 $K N(l)$ は温度一定なれば一定 値となる定数で，これより夜相の化学平衡組成，平衡反応率，与反応系の全圧力も計算できる。結局気相反応の分圧 平衡佰数 $K_{p}$ と各成分の蒸気压の数值から液相反応の化学平衡の状熊を計算することができることになる。

最近簡単な無譏および有機化合物特炕各種炭化水素の 蒸気の熱力学的数值は多数蓄棈整理されているので', 気相反応の化学平衡組成の計算は容易になった。しかし 没体の数值はな赫弱で，たとえあったとしても常温附 近の数値しか見当らないのが普通である。したがってス 手容易な蒸気の熱力学的数值と蒸気王の数值から, 液相 の化学平衙組成を計算する方法とその適用例を報告しよ 3と思引。

\section{気相の化学平衡恒数と柔気圧より液相の 化学平衡を計算す石式}

いま与克られた采が気液兩相より成り，両相の間には 蒸発平衡がなりたち, 各相においては化学平衡が成立し ているすのとする。また気相は理想気体，液相は理想溶 液として取报えるるのと仮定する。

$$
a A+b B=c C+d D
$$

理相溶萑火和いては Raoult の法䐓により成分 $A, B$, $C, D$ の気相に和ける分圧 $\bar{P}_{A}, \bar{P}_{B}, \bar{P}_{O}, \bar{P}_{D}$ !はそれぞれ その液相に和汾子率 $x_{A}, x_{B}, x_{C}, x_{D}$ とその蒸気压 $P_{A}, P_{B}, P_{O}, P_{D}$ との有に相等しい。

$$
\bar{P}_{A}=x_{A} P_{A}, \quad P_{B}=x_{B} P_{B}
$$

てたがって分殴平衡恒数 $K_{p}$ は

$$
\begin{aligned}
K_{p}=\frac{\bar{P}_{o}{ }^{c} \cdot \bar{P}_{D^{d}}}{\bar{P}_{A}{ }^{a} \cdot \bar{P}_{B}{ }^{b}} & =\frac{x_{Q}^{c} x_{D^{d}}}{x_{A}{ }^{a} x_{B}{ }^{b}} \times \frac{P_{O}^{c} P_{D^{d}}}{P_{A}{ }^{a} P_{B}{ }^{b}} \\
& =K_{N}(l) \cdot K_{\text {V.D. }}
\end{aligned}
$$

ここに $K_{N}(l):$ 波相の分子率平衙垣数

\footnotetext{
* 昭和 29 年6月12 日受理

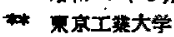

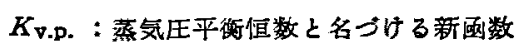

$K_{p}$ は温度一定なれば一定值， $K_{\text {V.p. }}$ は蒸気圧の比で あるから、これる温度一定なれば一定值である。したが って $K_{N}(l)$ は一定温度では一定值となる。

一力気相の化学平矢については

$$
K_{p}=K_{N(v)} \cdot \pi^{\Delta n}
$$

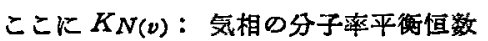

$$
\begin{aligned}
& \pi \quad \text { : 全圧为 } \mathrm{atm}
\end{aligned}
$$

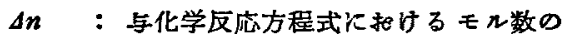

$$
\begin{aligned}
& \text { 代数和, す木b和 }(c+d)-(a+b)
\end{aligned}
$$

(4) 式よりあきらかなようK KN(v) は温度および全 卧水より变化する。(3)，(4) 式より

$$
K_{N(l) / K_{N(v)}}=\pi^{\Delta n / K_{\text {V.p. }}}
$$

次気液㕯相が蒸発平衡就よび化学平衙に在る場合の 自由度 $F$ を検討方ると，相の数 $P$ は2であるから

$$
F=C+2-P=C
$$

すなわち自由度独立成分の数しかない。したがって 各独立成分の比を決めると残された自由度は 1 つしかな い。したがって温度を決めれば系の他の性䝿はすへてお

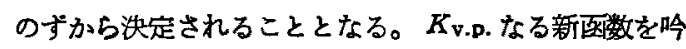
味してみる。

Table 1 Variation of $\log K_{\text {v.p. }}$ with Temp. and No. of $C$ atoms in the Polymerization of $n$-Olefins.

$$
\begin{array}{llll}
\log K_{\text {V.D. }} & 500^{\circ} \mathrm{K} & 600^{\circ} \mathrm{K} & 700 \% \mathrm{~K} \\
\log \left(\boldsymbol{P}_{\text {O20 }} / \boldsymbol{P}_{\text {O20 }}{ }^{2}\right) & -2.310 & -2.419 & -2.552 \\
\log \left(\boldsymbol{P}_{\text {O30 }} / \boldsymbol{P}_{\text {O10 }} \cdot \boldsymbol{P}_{\text {O20 }}\right) & -2.420 & -2.550 & -2.718
\end{array}
$$


いまオレフィンの重合反応を例にとって新函数 $K_{\text {v.p. }}$ を吟味してみる。

$$
\begin{gathered}
2 n-\mathrm{C}_{10} \mathrm{H}_{20}=n-\mathrm{C}_{20} \mathrm{H}_{40}, \\
n-\mathrm{C}_{10} \mathrm{H}_{20}+n-\mathrm{C}_{20} \mathrm{H}_{40}=n-\mathrm{C}_{30} \mathrm{H}_{60} \\
\log K_{\text {v.D. }}=\log \frac{P_{O 20}}{P_{C 10}{ }^{2}}, \\
\log K_{\text {v.p. }}=\log \frac{P_{O 30}}{P_{O 10} \cdot P_{O 20}}
\end{gathered}
$$

$500,600,700^{\circ} \mathrm{K}$ における計算結果を示すと第 1 表の

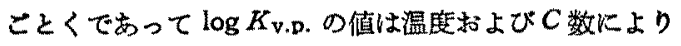
著しく変化しない。

次に匤力の影噄を椧討する。高生下の平衡を論ずる場 合は圧力の代りに逃散能 Fugacity を用いるのがよいと されている2 。

いま $\bar{f}_{i}$ : 気相报よび渡椙中任意成分 $i$ の逃散能

$f_{\pi i}:$ 任意成分 $i$ 純䊀液体として与荣之同温 $T$, 同压 $\pi$ 下に在ると仅定した場合の逃 散能（高圧下の蒸気圧沉対応）

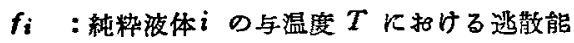
(正常蒸気压淿応)

$K_{f \pi}: F_{\pi i}$ をむって平衡恒数と同倳に表わした 比例項 ( $K_{\text {v.p. }}$ 江対度)

承散能の法則により

$$
\begin{aligned}
& \bar{f}_{i}=x_{i} \cdot f_{\pi i} \\
& K f_{n}=\frac{x_{\sigma}^{c} \cdot x_{D}^{d}}{x_{A}^{a} \cdot x_{B}^{b}} \times \frac{f_{\pi \sigma^{c} \cdot f_{\pi_{D}}}}{f_{\pi_{A}}{ }^{a} \cdot f_{\pi B}^{b}} \\
& =K_{N(l)} \cdot K_{f n}
\end{aligned}
$$

$f_{\pi i}$ は次式により 全王力 $\pi$, 正常蒸気生 $P_{i}$, 温度 $T^{\circ}$ $\mathrm{K}$ 压力 $\pi \sim P_{i}$ 間の平均分子容 $v_{i}$ から計算される ${ }^{32}$ 。

$$
f_{\pi i}=f_{i} \cdot e^{\frac{v_{i}\left(\pi-P_{i}\right)}{R T}}
$$

\section{計 算 例 1}

上述の計算式を実際の反泣例心ついて模证してみよ 3.

実際の反応は原料が純物質なれば反応内容が複雑であ り，反応が簡単なれば原料が混合物であったりして，簡 単な適例は少ない。以下著者の研究した実碒結果につい て適用を試みる。

挴順頁岩軽油の高王気相水素添加分解に捛いてては反応 筒の前に予借水素添加筒を置き固定触媒により液相水素 添加を行って成功を收めだ》。この予備水素添加の反応 条件を示方と反応温度 $300 \sim 370^{\circ} \mathrm{C}$, 反応压力 200 atm であって，高温高圧下の蒸発事す計算したころ乾点以下 であって，反応相は液相であると結論された。原料軽油 は約 40\% のオレフィンを含むか，この予備水菜添加工 程中にて大部分水添飽和されるが，完全には水素添加さ
れないことがわかった。この実験結果に対し平衡論的桧 討を加えてみる。

$$
\mathrm{C}_{n} \mathrm{H}_{2 n}(l)+\mathrm{H}_{2}=\mathrm{C}_{n} \mathrm{H}_{2,+2}(l)
$$

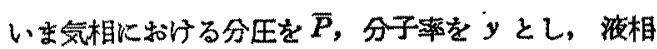

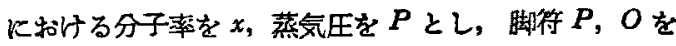
もってバラフィン，オレフィンを表わせば

$$
\begin{gathered}
\bar{P}_{P}=y_{P} \pi=x_{P} P_{P} \\
\bar{P}_{O}=y_{0} \pi=x_{O} P_{D} \\
\therefore \frac{y_{P}}{y_{O}}=\frac{x_{P}}{x_{O}} \times \frac{P_{P}}{P_{D}}
\end{gathered}
$$

さて同一炭菜数のバラフィン，オレフィンの蒸気压 $P_{P}, P_{O}$ はほぼ相等しいから

$$
P_{P} / P_{0} \cong 1 \quad \therefore y_{P} / y_{O} \cong x_{P} / x_{0}
$$

すなわち本例炕おいては気液再相に和けるパラフィン とオレフィンの比社添は相等しい。しかるに前記高开夈 秦添加の反応条件下ではオレフィン蒸気の水添館和に上 るバラフィン蒸気生成反応の平衡は $100 \%$ 生成系バラフ ィン側に偏っている。・

したがって液板反応に㧅いても100\%生成系に向って 進行するはずである。したがって大部分水添されるがー 部残るといら実鈳結果仕平衡畣的理由によるものでない ことがわかる。予借水添筒内では温度の上昇とともに蒸 発率を增大する。蒸発した蒸気は水素ととすに気泡とし て触媒と接触せず上昇し（筒内の固定触媒は液状油膜て 被覆されているので気泡と触媒とは直接接触しない) 数 10秒で筒内を通過する。したがって蒸発した蒸気中のオ レフィンの水添飽和は起り難い。これがたとえ予備水添 筒を設置してる原料軽油中のオレフィンが $100 \%$ 水添館 和されない理由であっだっ。

\section{計 算 例 2}

撚順の精製真岩軖油 $\left(230 \sim 280^{\circ} \mathrm{C}\right.$ 溜分、オレフィン 含量䄪 40\%) を活性白土䄪 10\% ととす数時間加熱す ると軽油中のオンフィンが重合する。加熱生成油を河 して白土を除いたのち真空分溜して重合油を採取しそ的 の天素価, 粘度, 粘度指数, 比重, 分子量なとの物性定 数を測定した。その結果軽油中のオレフィンが重合して Dimer, Trimer を生成するすのであることがわかっ た。反応温度と収率との関係を調べたところ $150^{\circ} \mathrm{C}$ 附 近上り相当の速度で重合し, $200^{\circ} \mathrm{C}$ 以上温度の上昇とと むに次第に収率を增大して約 $250^{\circ} \mathrm{C}$ 附近にて最高值 25

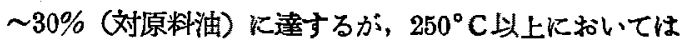
温度の上昇ととす汉率を急激に减少した。反応系の圧 力は溜分の高低に上り異なるが $200^{\circ} \mathrm{C}$ 附近では常王下 で進行し(逆流冷却器を附すればたりる), 250 300 $\mathrm{C}$ では数气圧となるので加压鉒を要した。 
Table 2 Equilibrium Conversion of Dimer and Trimer Formation in the Liquid Phase Polymerization of Higher $n$-Olefins in the Prasence of 1.5 times Saturate Hydrocarbons

\begin{tabular}{|c|c|c|c|c|}
\hline No. & & $500^{\circ} \mathrm{K}$ & $600^{\circ} \mathrm{K}$ & $700^{\circ} \mathrm{K}$ \\
\hline 1 & $2 n-1-\mathrm{C}_{10} \mathrm{H}_{20}=n-1-\mathrm{C}_{20} \mathrm{H}_{40} \log K_{p}$ & 0.781 & -0.627 & -1.626 \\
\hline 2 & $2 n-1-\mathrm{C}_{14} \mathrm{H}_{28}=n-1-\mathrm{C}_{28} \mathrm{H}_{56} \log K_{p}$ & $\pi$ & $"$ & " \\
\hline 3 & $\begin{array}{l}\text { Difference between } \log K_{f} \text { of } n-1-\text { Olefin and } \log \\
K_{f} \text { of } n-2-, n-3-\text { Olefins }\end{array}$ & -0.723 & -0.550 & -0.418 \\
\hline 4 & $2 n-2-\mathrm{C}_{14} \mathrm{H}_{28}=n-2-\mathrm{C}_{28} \mathrm{H}_{58} \quad \log K_{p}$ & +0.058 & -1.177 & -2.044 \\
\hline 5 & $\log K_{\forall . D .}=\log \left\{P_{Q_{28}} / P_{O_{14}{ }^{2}}\right\}$ & -2.286 & -2.358 & -2.510 \\
\hline 6 & $\begin{aligned} \log K_{N(l)} \text { of Reaction No. } 4 \text { above } & =\log K_{p}-\log K \text { v.p. }\end{aligned}$ & $+2,344$ & +1.181 & +0.466 \\
\hline 7 & $-\log n, n$ (No. of monomer isomers) $=15$ & -1.176 & -1.176 & -1.176 \\
\hline 8 & $\log K^{\prime} N(l)=\log K N_{(l)}-\log n$ & +1.168 & +0.005 & -0.710 \\
\hline 9 & $\begin{array}{l}\text { Equilibrium conversion } x \text { (mol fraction) of Dimer } \\
\text { formation, } n=15\end{array}$ & 0.767 & 0.400 & 0.126 \\
\hline 10 & $\begin{array}{l}\text { Equilibrium conversion } x \text { of Dimer and Trimer } \\
\text { formation, } n=15\end{array}$ & 0.852 & 0.416 & 0.126 \\
\hline 11 & Yields of Polymers for Reactants $x \times 40 \%$ & 34 & 16.6 & 5.0 \\
\hline
\end{tabular}

初め反応温度の上㫒ととあに重合油汉率の増加したの は反店速度の向上に基くるのと説明しうるがなぜ 250 ${ }^{\circ} \mathrm{C}$ 附近にて仅率に極大值を生ずるのか？この極大值 がなせ 40\% でないのか？高温にて収率の減少するの はオレフィンの重合反応が発荎反応で高温では平衡が不 利となるためであると定性的に理解しろるが，なゼ 250 ${ }^{\circ} \mathrm{C}$ 以上で収承の低下が始まるのか：以下本報の計算 式を利用し計算を行って定量的説眀を試みよ5。

\section{1) 不応模型の設定}

平衡論的考察の Key point は可及的精確な最近の熱 力学的数值（標隻生成自由エネルギー $\Delta F^{\circ}{ }_{\boldsymbol{g}}$, 標準生成 反応の平衡恒数 $K_{f}$ など）を使用することと可及的真相 に近い反応模型を設定して計算を試みることである。

頁岩軽油，ガソリンの性状，水素添加その他の研究か ら頁岩油中のオレフィンの主成分惊オレフィンかむる いは分忮度の低いオレフィンであると結論されている。 原料軽油の留出温度からみてその成分炭化水素の炭素数 を $\mathrm{C}_{19}, \mathrm{C}_{14}, \mathrm{C}_{15}$ と推定する。原料軽活中のオレフィン の主成分を正オレフィンとし，その $\mathrm{C}=\mathrm{C}$ 結合は炭素鎖 の端になく，端より中に在るるのと推定する。その理由 はn-1-オレフィンの $K_{\boldsymbol{f}}$ はn-2-オレフィン, $n$-3-オレ フィンに比して相当小さいこと, 頁岩油は $600^{\circ} \mathrm{C}$ 附近 の乾溜生成物であるから C=C の位置は平衡論的要求に したがって分布しているであろうと考光られることに基 く。この $\mathrm{C}=\mathrm{C}$ 結合の位盢の異性体を $\mathrm{C}_{13}, \mathrm{C}_{14}, \mathrm{C}_{15} \mathrm{k}$ つき各5筬とすると，原料軽油中に存在するオレフィン の分子種は $3 \times 5=15$ 简となる。

以上の考察か、ら $K_{f}$ その他を計算するための代表反応 を次のことく定める（n-2-オレフィシ，n-8-オレフィン $の \log \mathrm{K}_{f}$ は近似している)。

$$
\begin{aligned}
& 2 n-2-\mathrm{C}_{14} \mathrm{H}_{28(l)}=n-2-\mathrm{C}_{28} \mathrm{H}_{56(l)} \\
& n-2-\mathrm{C}_{14} \mathrm{H}_{28(l)}+n-2-\mathrm{C}_{28} \mathrm{H}_{56(l)} \\
&=n-2-\mathrm{C}_{42} \mathrm{H}_{84(l)}
\end{aligned}
$$

\section{2) 代表及流の平衡恒数 $\boldsymbol{K}_{p}$}

n-1-オレフィンの $\log K_{f}$ の值は $\mathrm{C}_{20}$ な゙ちえれて いるが， n-2-オレフィン，n-3-オレフィンなどの log $K_{J}$ の值は $\mathrm{C}_{6}$ ましか与えられていない。よって同型 反応は近似した熱力学的函数值を有するとい5通則を利 用して代表反応の $\log K_{p}$ を求めることにする。

高級 $n$-1-オレフィンの $\log K_{f}$ は $\mathrm{CH}_{2} 1$ 箇增すこと に一定值 $\left(\Delta \log K_{f}\right)$ を增加して行く。したがって高級 n-1ーオレフィンの重合反底の $\log K_{p}$ の值はC 数に無 夙係比一定值をとる。いま $n-1-\mathrm{C}_{10} \mathrm{H}_{20}$ の重合によるn $-1-\mathrm{C}_{20} \mathrm{H}_{40}$ の生成反応の $\log K_{p}$ を与反広各成分の $\log$ $K_{f}{ }^{12}$ の代数和として求めると第 2 表 第 1 行の数值とな る。この $\log K_{p}$ の值はこのま立代表反応の $\log K_{p}$ の 值（第，2表第，2行）として採用しうる。

次に゙ $n$-八キ七ン各異性体の $\log K f^{2)}$ の值を比較する と $\mathrm{C}=\mathrm{C}$ が端にあるn-1ーへキセンよりも中にある $n$-2ヘキセン，n-3ーへキセンの方がかなり大きく窄定であ る。しかもn-2-とn-3-との值の差は比皎的小さい。 いま $n$-1ーへキセンを $n$-シスー2-, $n$-トランスー2-. $n$ ーシスー3-, n-トランスー3ーへキャンとの差が $n-\mathrm{C}_{14} \mathrm{H}_{2 \mathrm{~s}}$ の 場合にる存在するとして代㜔反応の $\log K_{p}$ を求めたの が算 2 表第 4 行の数值である。

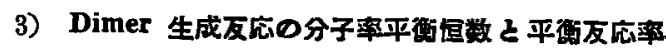




\section{との関保}

いま恒温恒王反応系にて当初原系はオレフィン $40 \%$ ， 飽和炭化水瑟I（不活性成分）60\%よりなるものとする。

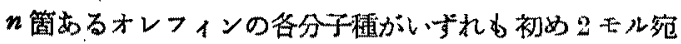
存在しその中 $2 x$ モルが反応して Dimer を生成し平衡 に達したとする( $n$ 箇のオレフィンの重合反応の $K_{p}$ は いずれる相等しいと仮定する)。平衡混合物中の各分子 種のモル数を示すと

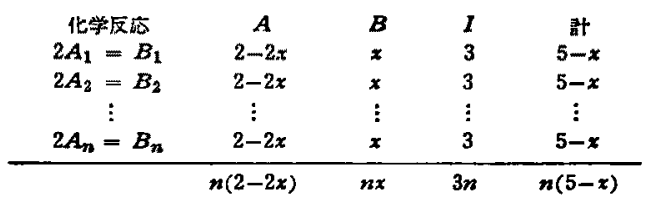

各成分の分子率

$$
\begin{aligned}
& N \quad \frac{(2-2 x)}{n(5-x)} \quad \frac{x}{n(5-x)} \quad \frac{3}{n(5-x)} \quad \frac{1}{n} \\
& \text { ここに } A: \text { monomer } \quad B \text { : Dimer } \\
& I: \text { 不活性成分 } \quad x: \text { 平衙反店分率 } \\
& K_{N}=\frac{N_{B_{1}}}{N^{2} A_{1}}=\frac{N_{B_{2}}}{N^{2} A_{2}}=\cdots \cdots=\frac{N_{B_{n}}}{N^{2} A_{n}}=\frac{n x(5-x)}{(2-2 x)^{2}}
\end{aligned}
$$

オレフィンの分子種 1 箇の場合の分子桼平衡恒数 $K_{N}$ は

$$
K_{N^{\prime}}=\frac{x(5-x)}{(2-2 x)^{2}}
$$

(19) と（20）とより

$$
K_{N} \div n=K_{N}^{\prime}
$$

あるいは $\log \mathrm{K}_{N}-\log n=\log \mathrm{K}_{N^{\prime}}$

（21）式からあきらかなよ5に分子種が $n$ 籄存在する 場合の各オレフィンの分子率平衡恒数 $K_{N}$ は分子種 1 箇の場合の分子率平衡恒数 $K_{N}{ }^{\prime}$ の $n$ 倍に等しい。別 報卧にしたがいオレフィンの分子種 1 筒のとき $x$ と $K_{N}{ }^{\prime}$ との関係曲線を作成して批けば，これを利用して分子種

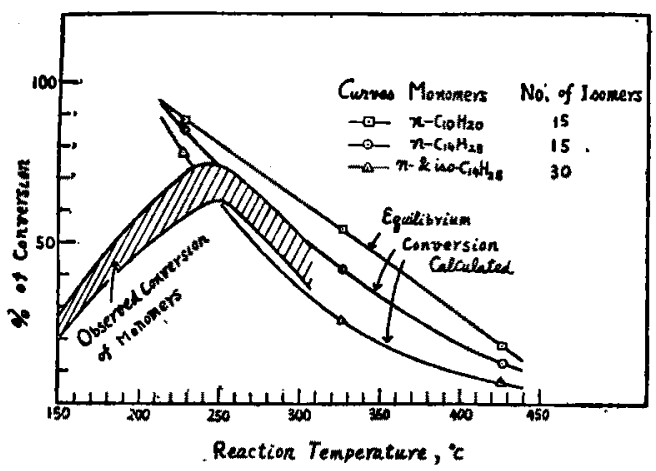

Fig. 1 Relation between Polymerization Temp. and Conversions of Monomers.

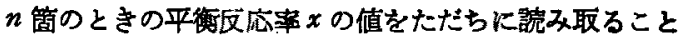
ができる。第 2 表第 5 行の $\log K_{\text {v.p. }}$ 江 $n-C_{14} \mathrm{H}_{28}, n-\mathrm{C}_{28}$ $\mathrm{H}_{58}$ の蒸気圧から求めた数值である。第 6 行は $\log K_{p}-$

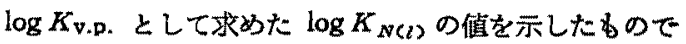
ある。第 8 行の値は $\log K_{N(l)}$ から $\log n ，(n=15)$ を 引いた值で上述の $\log K_{N^{\prime}}$ に当る。

第 9 行は $\log K_{N^{\prime}}$ と $x$ との関係曲線から求めた平梅 反応率 $x$ の倠である。

上の反応模型は Dimer の生成のみを考えたから未た 事实之相遠している。よって次にDimer, Trimer の生 成を考えることにしよう。いまオレフィンの分子種 1 简 の場合を採り上げる。 $n$ 䈏共存する場合は上述のことく 1 䉪の場合から計算できるからである。

$$
\begin{aligned}
& 2 A=B \\
& A+B=C
\end{aligned}
$$

Monomer, Dimer, Trimer の分子率を $N_{A}, N_{B}$, No とすると，

$$
\begin{aligned}
& K_{N}=N_{B} / N_{A}^{2}=N_{O} / N_{A} N_{B} \\
& N_{B}=K_{N} N_{A}^{2}, N_{C}=K_{N}^{2} N_{A}^{3} \\
& N_{A}+N_{B}+N_{O}+N_{I}=1
\end{aligned}
$$

Dimer 1 分子は monomer 2分子より, Trimer 1 分子は monomer 3 分子から生成されるので, 当初の monomer $A$ と不活性成分 $I$ とのモル比は

$$
\frac{N_{A}+2 N_{B}+3 N_{O}}{N_{I}}=\frac{2}{3}
$$

（24）（26）を（25) 式に代入すると（0< $\left.N_{A}<0.4\right)$

$$
\begin{aligned}
& 2.5 N_{A}+4 K_{N} \cdot N_{A}^{2}+5.5 K_{N^{2}} \cdot N_{A}^{3}-1=0 \\
& x=1-\left\{N_{A} /\left(N_{A}+2 N_{B}+3 N_{o}\right)\right\}
\end{aligned}
$$

(27）式に第 2 表第 8 行の $\log K_{N^{\prime}}$ の值を代入して解 けば $N_{A}$ の值がえられる。この $N_{A}$ の值を (28) 式代 入れると平衡反応率 $x$ の値がえられる。第 2 表第10行の 值はこのようにして求めた值である。Dimer のみ﨡 成する場合の $x$ と，Dimer のほか汇 Trimer を生成す る場合の $x$ とを比較すると， $K_{N}$ の值が大きい場合は後 者の方が大きいが， $K_{N}$ の傎が小さくなると両者の值は ほとんど等しくなる。

平衡反応率 $x$ にオレフィンの含有率 $40 \%$ を乗ずれば重 合油の収率 (対原料泊\%) がえられる(第2 表第11行)。

4）オレフィンの分子揫の数と収率との関㖨

オレフィン重合とおいててイソオレフィンす存在し重合 に与かると仮定し $n=30$ とした場合およびオレフィンの C数を $\mathrm{C}_{10}$ に小さくした場合について上述の計算を繰返 し一括比較表および図に示寸と第3 表および萧 1 国のこ そくで㔖る。

\section{5）計算結果の考察}

1. 不飽和軽油の重合による重合油の理論収率は重合 
Table 3 Relation between yields of polymers and Numbers of Oletin Isomers in the Liquid Phase Polymerization in the presence of 1.5 times Saturate Hydrocarbons.

\begin{tabular}{|c|c|c|c|c|c|c|}
\hline Olefin Reactants & & 227 & 250 & 306 & 327 & $427^{\circ} \mathrm{C}$ \\
\hline $\begin{array}{l}n-C_{14} H_{28} \\
\text { No. of Olefin } \\
\text { Isomers } n=15\end{array}$ & $\begin{array}{l}\log K_{N^{\prime}}(\underline{ }) \\
x \text { (mole fraction) } \\
\text { Yields of Polymers } \% \\
\text { Total pressure } \pi \text { atm }\end{array}$ & $\begin{array}{c}1.168 \\
0.852 \\
34 \\
0.48\end{array}$ & $\frac{-}{29}$ & $\overline{20}$ & $\begin{array}{l}0.005 \\
0.416 \\
16.6 \\
3.8\end{array}$ & $\begin{array}{l}-0.710 \\
0.126 \\
5.0 \\
-\end{array}$ \\
\hline $\begin{array}{l}n-\mathrm{C}_{14} \mathrm{H}_{28} \\
n=30\end{array}$ & $\begin{array}{l}\log K_{N}{ }^{\prime}()^{2} \\
x \text { (mole (raction) } \\
\text { Yields of Polymers } \%\end{array}$ & $\begin{array}{l}0.867 \\
0.78 \\
31\end{array}$ & $\overline{25}$ & $\overline{14}$ & $\begin{array}{c}-0.296 \\
0.256 \\
10.2\end{array}$ & $\begin{array}{r}-1.011 \\
0.068 \\
2.7\end{array}$ \\
\hline $\begin{array}{l}n-C_{10} \mathrm{H}_{30} \\
n=15\end{array}$ & $\begin{array}{l}\log K N^{\prime}(\mathcal{l}) \\
x \text { (mole fraction) } \\
\text { Yields of Polymers \% } \\
\text { Total pressure } \pi \text { atom }\end{array}$ & $\begin{array}{l}1.302 \\
0.88 \\
35 \\
4.0\end{array}$ & $\overline{32}$ & $\bar{z}$ & $\begin{array}{c}+0.201 \\
0.54 \\
21.6 \\
14\end{array}$ & $\begin{array}{l}-0.505 \\
0.81 \\
7.2 \\
-\end{array}$ \\
\hline
\end{tabular}

$x$ : Equilibrium conversion of monomers, mole fraction.

$K_{N^{\prime}(l)}$ : Mole fraction equillbrium constant in the liquid Phase reaction. Polymers denote dimers and trimers. Yields of Polymers were expressed as $\%$ for reactants which contained $40 \%$ of Olefins.

温度の上异とともに減少する。 $250^{\circ} \mathrm{C}$ 附近の平衡反応率 を内挿して求めると $64 \sim 71 \%$ であるから実測最高収察 からの計算值 63〜75\% と注ぼー致する。したがって $250^{\circ} \mathrm{C}$ 以下の低温部活ける温度上昇炕伴 5 収率增加は 反広速度の上年に胄来するるのであり，250 $\mathrm{C}$ 以上の高

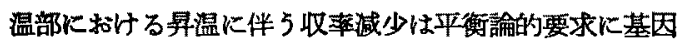
するすのである。

2. 原料軽油の溜分を狭くすると含有されるオレフィ ンの分子種の数が少くなるから重合油の理論収率はやや 増加する。

3、 反応禾の全王の計算値を実際の测定值をよく説明 する。

結局, 頁岩軽油を活性白土で液相重合亏る実駼結果は 本報による計算によって定量的に説明されたのみなら ず,工業的に重要な因子を明確に把握することができ た。

\section{Nomenclature}

$K_{p}$ : Partial pressure equilibrium constant.

$K_{N(v)}$ : Mole fraction equilibrium constant in the vapor phase.

$K_{N(l)}$ : Mole fraction equilibrium constant in the liquid phase.

$\mathrm{K}_{N} \quad$ : Mole fraction equil. const., number of Olefin iomers being $n$ pieces:

$K_{N^{\prime}}$ : Mol fraction equil. const., number of olefin isomer being single.
$K_{\text {v.p. }}$ : Vapor pressure equil.c onst, new function proposed.

$I \quad$ : Inert component in the reaction

$P_{A}, P_{B}$ : Normal vapor pressure of component $A, B \cdots$ respectively.

$\bar{P}_{A}, \overline{P_{B}}$ : Partial pressure of component $A, B \ldots$ respectively.

$N_{A}, N_{B}$ : Mole fraction of component $A, B \cdots$ respectively.

$n$ : Number of Olefin isomers.

$x \quad$ : Equilibrium conversion (mole fraction)

$x_{B}, x_{B}$ : Mole fraction of component $A, B \cdots$ in the liquid phase respectively.

$y_{A}, y_{B}$ : Mole fraction of component $A, B \ldots$ in the vapor phase respectively.

$\pi \quad$ : Total. pressure, atm.

\section{Reference}

1) American Petroleum Institute Research Project 44, Selected valnes of physical and thermodynamic properties of hydrocarbons and related compounds, Carnegie Press, 1953)

2) Souders, Selheimer \& Brown, Ind. Eng. Chem., 24 (1932) ; Hougen \& Watson, Chemical Process Principles, John Wiley \& Sons, Inc., 1943, 629.

3) Hougen \& Watson, ibid, 623

4) Morikawa \& Takagi : This J. 18, 120 (1954)

5) K. Morikawa : "Chart to read Equilibrium Conversion from Equilibrium Constant", will be published shortly in this Journal. 


\section{Method of Calculation of Equilibrium Conversions of Liquid Phase Reactions}

\section{Kiyoshi Morikawa*}

Accurate thermodynamic date of simple gases and vapors of various kinds of hydrocarbons have been accumulated and are available nowadays in the tabulated forms ; and yet the similar data for liquid state are still very scanty and so they are not available for equilibrium calculations.

Consider the gas phase and the liquid phase, both of which exist in the vaporization equilibrium as well as in the chemical equilibrium within each phase ; and, furthermore, assume the ideal bechaviors of gas phase (ideal gas) and liquid phase (ideal solution); and, then, the following simple equation can be very easily derived from Rault's law.

$$
\begin{array}{ll} 
& K_{p}=K_{N\langle l)} \cdot K_{\text {v.p. }} \\
\text { or } \quad & \log K_{p}=\log K_{N(l)}+\log K_{\text {v.p. }}
\end{array}
$$

Here $\quad K_{p}:$ partial pressure equilibrium constant.

$K_{N(2)}$ : mole fraction equilibrium constant in the liquid phase reaction.

$K_{\text {v.7. }}$ : new function named vapor pressure equilibrium constant, which is expressed in the same way as the equilibrium constant, by means of vapor pressure of each component in the given reaction.

$K_{N(l)}$ and $K_{v . p .}$ are the unique function of temperature, and are independent of the total pressure of the reaction system.

It was found that the variation of $\log K_{\text {v.p. }}$ with temperature and with number of carbon atoms of reactants and products in the same kinds of reaction was rather small as exemplified in Table 1

Log $K_{p}$ of the reaction can be calculated from the equilibrium constant of formation of each

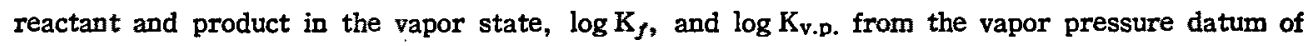
each liquid component concerned, and thus the values of $\log K_{N(l)}$ can be calculated from the available thermodynamic data.

In the case of liquid reactions under high pressure, the pressures may be replaced by fugacities and thus better results may be expected.

* Tokyo Institute of Technology

\section{問 題 解 决の鍵は？}

われわれが研究室あるいは工場で研究試鍳する場合, どらして閣題を解決する方法を見出そらかと苦心する。 ここにいら方法とはもちろん科学技術的な方法である が，その偂に思考的方法諭に考虚すでき問題がするので はないだる5か？問題とは解決困難岁現象である。こ の現象が哞生した原因は何か？原因を追求すると幾多 の因子が考えられるが，その内どれが重要な支配因子で あるかを究明する。これがためには適当な科学技術上の 方法を撰択傎用して実駼を行い計算をする。そらして問 題を支配する主要因子とその作用機碝があるらかになれ ば，問題を解洪する奶策は自ら生れ，ここに問題は解決

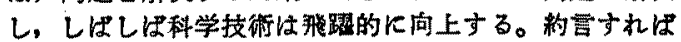
問題を支配する主要な因子をすきらかにすることが問題
を解決する鍵の一つですると思ら。われわれの先翌は皆 こらした苦心を抬い，こらした方法を採って問通を解決 し，今日の科学拉衔を策さ上げて来られた。これは一見 容易簡単下見える。しかし具体的な問题下自分自身がぷ

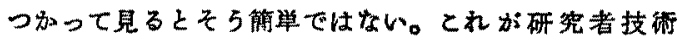
者の侰念と,ぬカとなるまでには，実際の苦い実践上の 体験を重私なりればならない。この科学技術的方法諭に 先行する思考的方法論の内容としては上部以外に沢山む る。それを体系化し普遍妥当な真理として，明瞭に意識 し，具体的実践に把いて検討を皘み重ねて行くなれは， われわれの侵念となり力となる速度は增し年限は短䑿さ れるのではないだるらか？

(K.M.生) 